\title{
Interesses de brancos em terras de negros
}

Maria Ester Santana Silveira Nascimento

\begin{abstract}
Resumo
Desenvolver economicamente, não se esquecendo da questão social, sem perder de vista a perenidade dos recursos naturais e sem penalizar as gerações futuras, é o dilema sobre o qual muitos se curvam atualmente. Há uma crise mundial, para a qual a solução tem o nome de Desenvolvimento Sustentável. Esse tema será o apoio para se faça uma análise acerca da realidade da cidade de Paracatu, Minas Gerais, evidenciando o conflito entre comunidades quilombolas e a mineradora local. Destacamse práticas de exploração ambiental, apropriação de recursos naturais, além da observação quanto a fragilidade da nova proposta: sustentabilidade.
\end{abstract}

\section{Palavras-chave}

Sustentabilidade. Mineração. Quilombolas.

1. Mestrado em Desenvolvimento Social pela Universidade Estadual de Montes Claros, professora na Faculdades Integradas Pitágoras de Montes Claros e na rede pública de ensino deste município. E-mail: msantanasn@ hotmail.com. 


\title{
Interest of white people on black's lands
}

Maria Ester Santana Silveira Nascimento*

\begin{abstract}
Maintaining the current economic development, turning his eyes to the social development without losing focus of the sustainability of natural resources and don't penalize the future generations is the dilemma that many thinkers, politicians, economists, scientists and ordinary people bow down before. There's a world crisis that the solution is called Sustainable Development. This theme will support, in order to do an analysis about the reality of Paracatu City, Minas Gerais emphasizing the conflict between maroon communities and the mining site. Practical environmental exploitation are also shine through, appropriation of natural resources, as well as observation of the fragility of the new proposal: sustainability.
\end{abstract}

\section{Keywords}

Sustainability. Mining. Maroons.

* Candidate for master's degree in Social Development at the State University of Montes Claros, professor at the Pitágoras Integrated Faculties and in the regional education at Montes Claros. E-mail: msantanasn@hotmail.com. 


\section{Introdução}

O que acontece quando comunidades quilombolas estão localizadas em espaços de interesses econômicos? A questão adequa-se à realidade de Paracatu, uma cidade conhecida tradicionalmente pela exploração aurífera e pela existência de comunidades quilombolas.

Nos anos de 1980, a mineração na cidade foi regulamentada pela empresa Rio Paracatu Mineração, extensão de uma empresa inglesa (Grupo inglês RTZ) no Brasil. Na mesma década, a promulgação de uma nova constituição brasileira deu destaque aos direitos das comunidades negras rurais sobre seus territórios. Essa situação expõe o paradoxo que vive a cidade de Paracatu. De um lado, a cidade tem na mineração, atividade predatória, parte de sua economia; de outro, comunidades quilombolas com importância cultural e cunho de preservação ambiental. Como pensar em sutentabilidade e desenvolvimento sustentável, nesse cenário?

Desenvolvimento sustentável tem sido a proposta da Organização das Nações Unidas (ONU) para a valorização da vida das atuais e futuras gerações, tendo como tema central a preservação dos recursos naturais; proposta adotada pelo Estado brasileiro, dentre várias outras medidas de preservação ambiental, com legislação específica em relação à sustentabilidade das comunidades quilombolas. Sustentabilidade tem sido palavra de ordem em empresas como a mineradora que desenvolve suas atividades em Paracatu.

No discurso vigente, sustentabilidade é uma palavra forte, mas que, às vezes, se apresenta sob uma fragilidade singular. É baseada nessa realidade que será analisado, neste trabalho, o que ocorre em Paracatu entre comunidades quilombolas e a mineradora estabelecida na cidade.

Na primeira parte, será apresentado, de forma resumida, um histórico da cidade quanto ao seu desenvolvimento econômico, destacando a atividade mineradora praticada. $\mathrm{Na}$ sequência, será analisada a questão sobre a riqueza do solo de Paracatu, a qual ainda não conseguiu suprir de forma integral suas necessidades socieconômicas.

Paracatu é uma cidade de tradição aurífera que tem como herança, em seu quadro social, maciça presença de remanescentes de quilombo, em frequente luta por seus direitos. No passado, esses grupos se alojaram em locais em que a mineração havia se exaurido, mas o presente trouxe uma nova realidade que acabou por colocar tais comunidades em confronto com a tecnologia e o interesse econômico.

Para o fechamento deste texto será apresentada uma visão histórica dos projetos de reordenação do processo exploratório dos recursos naturais desenvolvidos pela ONU, chegando à proposta do momento de "Desenvolvimento Sustentável", com críticas negativas e positivas acerca dessa nova proposta.

\section{Sobre Paracatu}

Caio Prado Júnior (1996), em sua obra Formação do Brasil Contemporâneo, assim se refere à situação da mineração (aurífera) brasileira no final do século XVIII e início do século XIX:

[...] foi além, na verdade, a indústria mineradora no Brasil nunca desta aventura passageira que mal tocava um ponto para abandoná-lo logo em seguida e passar adiante. E é esta a causa principal por que, apesar da riqueza relativa avultada que produziu, drenada aliás toda para fora do país, deixou tão poucos vestígios, a não ser a prodigiosa destruição dos recursos naturais que semeou pelos distritos mineradores e que ainda hoje fere a vista do observador; [...] serão estrangeiros, em particular ingleses, aos quais se permite o estabelecimento nas minas 
em 1824, que vão recolher o triste espólio da aventura passada, e infundir um novo embora leve alento na indústria brasileira da mineração. (PRADO JúNIOR, 1996, p. 171).

O que acontece em Paracatu parece não fugir a esse comentário. Localizada no noroeste de Minas Gerais, a cidade faz vizinhança com os municípios Unaí, João Pinheiro, Lagoa Grande, Guarda-Mor e Vazante, no estado de Minas Gerais; em Goiás, com Cristalina e Campo Alegre de Goiás. Dista 482Km de Belo Horizonte e $233 \mathrm{Km}$ de Brasília-DF. Pertence à história da mineração brasileira e, exatamente por sua riqueza aurífera, foi elevada à condição de vila em 1798, por um alvará de D. Maria I. De Arraial de São Luiz e Sant'Anna das Minas de Paracatu, passou a Paracatu do Príncipe. Assim como outras regiões auríferas, viu reduzida a quase nada sua produção, no final do século XVIII. Como alternativa aos tempos áureos, o município desenvolveu a atividade pecuária e a agricultura rudimentar.

A construção de Brasília em uma região próxima, na metade do século $X X$, trouxe nova movimentação à cidade. Mesmo fraca, a mineração permaneceu sendo praticada por iniciativas particulares, de forma rudimentar e artesanal, com o agravante do uso do mercúrio. Como prevenção a problemas mais sérios como a poluição dos córregos regionais e aumento de doenças ligadas ao uso do referido produto, a prefeitura suspendeu a atividade mineradora, embora essa tenha continuado a ser praticada de maneira clandestina. Na década de 1980, a empresa Rio Tinto, parte brasileira de uma empresa inglesa, instalou-se na cidade com o nome de Rio Paracatu Mineração.

A regulamentação da extração, a contratação de trabalhadores e profissionais graduados da própria cidade, a vinda de profissionais estrangeiros, a destinação de verbas para melhorias na cidade - aí incluída a construção de museus, bem como a recuperação de parte do patrimônio histórico - representaram inestimável contribuição para que a cidade desse um grande salto em seu desenvolvimento econômico. Rapidamente, toda a cidade viu surgirem, por todos os lados, concorrendo com sua antiga estrutura colonial, os benefícios do progresso.

A realidade de Paracatu, em relação à mineração, tem um relevante traço paradoxal: de um lado, a cidade foi e tem sido beneficiada com a regulamentação da mineração através da empresa aí estabelecida; de outro, expressa a dúvida quanto ao real retorno econômico dessa exploração e a herança que por ela será deixada em seu universo sociocultural. Além desse, outros dois paradoxos são evidentes. O primeiro deles é que no local que hoje é de maior interesse para a exploração aurífera boa parte das comunidades negras rurais estão estabelecidas há séculos; o segundo é que no mesmo período em que ocorria a regulamentação para o estabelecimento da mineradora Rio Tinto Mineração na cidade - década de 1980 -, há poucos quilômetros dali, em Brasília, uma nova constitução era elaborada para o país contendo em seu texto a máxima expressão de retratação para com essas comunidades, vítimas históricas do desprezo, do desrespeito e da exclusão.

\section{Índices de pobreza, mesmo com tanta riqueza mineral}

Em Paracatu, a pobreza do povo se combina perigosamente com a riqueza da terra e as estratégias agressivas de penetração dessa mineradora internacional, que está buscando aqui um paraíso de contaminação. (ULHOA, $\left.2007^{2}\right)$.

No prefácio de sua obra Desenvolvimento como Liberdade, Sen (2008) ressalta que vivemos, hoje, em um mundo de opulência sem precedente, ao mesmo tempo em que vivemos num mundo de privação, destituição

2. Fragmento do discurso de Sergio Danni Ulhoa proferido na Câmara Municipal de Paracatu em abril de 2007. 
e opressão extraordinária, e que isso acontece pelo mundo todo, independente de ocorrer em país rico ou pobre. Vive-se, hoje, entre a pobreza extrema e a riqueza. A superação desse tipo de problema, segundo o autor, dar-se-á pelo desenvolvimento, que consiste

na eliminação de privações de liberdade que limitam as escolhas e oportunidades das pessoas de exercer ponderadamente sua condição de agente. (SEN, 2008, p. 10).

Muitas pessoas que vivem em Paracatu, julgam haver, no município, um desequilíbrio entre a riqueza que a mineradora extrai da região ${ }^{3}$ e as condições em que boa parte da população vive. Tal fato pode ser notado quando se observam índices como o IDH (Índice de Desenvolvimento Humano) da cidade, que é de 0,760\%, somado ao índice de analfabetismo que é de $12,20 \%{ }^{4}$. Se comparada à taxa de analfabetismo do país que é de $10,00 \%$, temos, em Paracatu, um índice de 20\% a mais e, em relação ao IDH, cuja taxa para o Brasil de 0,813, Paracatu está 7\% inferior. Índices de pobreza em meio à exploração de tanta riqueza geram dúvidas quanto à redistribuição dos benefícios. Essa preocupação com a transformação da riqueza em melhorias da condição de vida da população, para muitos, inclusiveparaSen(2008), éumproblemamundial.

Um número imenso de pessoas em todo o mundo é vítima de várias formas de privação de liberdade. [...] muitas pessoas têm pouco acesso a serviços de saúde, saneamento básico ou água tratada, e passam a vida lutando contra uma morbidez desnecessária, com frequência sucumbindo à morte prematura. Nos países mais ricos é demasiado comum haver pessoas imensamente desforecidas, carentes das oportunidades básicas de acesso a serviços de saúde, educação funcional, emprego remunerado ou segurança econômica e social. (SEN, 2008, p. 29).

Mas o que é a pobreza? Sen (2008) considera pobres aquelas pessoas privadas de liberdade e impedidas de escolhas e de desenvolvimento de suas capacidades. Para Rahnema (2000, p. 229), a pobreza étambém um "mito, umaconstruçãoeoinventodeumacultura".

O movimento histórico do Ocidente, sob a bandeira da evolução/progresso/crescimento/ desenvolvimento, descobriu as necessidades. Mais tarde impôs aos demais. (ILLICH, 2000, p. 156, grifo do autor).

Para esses "demais", descobrir-se necessitado também os fez descobrir-se pobres e subdesenvolvidos. A origem disso está relacionada com o fim da segunda Guerra Mundial e à ascensão dos Estados Unidos da América como representante do desenvolvimento econômico mundial, a partir da década de 1940. O presidente Harry Truman oficializou essa separação entre "eles" e "nós", os pobres e os ricos, em seu discurso de 20 de janeiro de 1949, no qual também assumia a responsabilidade de tirar os pobres e subdesenvolvidos dessa condição. A partir de então, começou-se um grande movimento para a superação dessa condição de subdesenvolvidos. Nações que nunca antes se viram como pobres passaram a buscar sua riqueza. Nascia o mito do desenvolvimento econômico, salvação para todos e quaisquer males da humanidade. Deixar de ser pobre era tornar-se igual aos países centrais - fato considerado difícil por Furtado (1981), uma

3. Atualmente são extraídas 17,2 milhões de toneladas de ouro, por ano, na mina em Paracatu. No entanto, em sua tese de doutoramento, Enríquez (2009) mostra que a empresa extratora contribui de CFEM (Compensação Financeira pela Exploração Mineral) para o município apenas $2 \%$ da receita total de Paracatu. Disponível em: $<$ http://www.kinross.com.br/projeto_expansao.php?id_category=5>.

4. Cf. PNUD (Programa das Nações Unidas para o Desenvolvimento). Atlas do Desenvolvimento Humano no Brasil. 2013. Disponível em: < http://www.pnud.org.br/IDH/Atlas2013.aspx?indiceAccordion=1\&li=li_Atlas2013 
vez que a maior parte dos recursos extraídos desses países era destinada aos países ricos. Igualar em consumo - porque para desenvolver é necessário consumir - entre esses dois lados seria o mesmo que decretar o fim da própria existência humana. Pobres não poderão ser como os ricos, não porque são incapazes, mas porque há muito já entregam suas riquezas.

Mas como negar que essa ideia tem sido de grande utilidade para mobilizar os povos da periferia e levá-los a aceitar enormes sacrifícios, para legitimar a destruição de culturas arcaicas, para explicar e fazer compreender a necessidade de destruir o meio físico, para justificar formas de dependência que reforçam o caráter predatório do sistema produtivo? (FURTADO, 1981, p. 75, grifos do autor).

O desenvolvimento econômico trouxe também a crença acompanhada da respectiva celebração de que seriam supridas as necessidades básicas sociais.

Escolas, hospitais, aeroportos, instituições correcionais ou para doentes mentais e a mídia poderiam ser definidas como uma rede de templos construídos para consagrar a destruição das necessidades e a reconstrução dos desejos em necessidades. (ILLICH, 2000, p. 158).

Passou-se de homo sapiens a homo miserabilis. A excessiva necessidade de consumo para a manutenção de conforto humano cegou boa parte da sociedade, desviando-a da

tarefa básica de identificação das necessidades fundamentais da coletividade e das possibilidades que, abrem ao homem o avanço da ciência. (FURTADO, 1981 p. 76).

Escolas, hospitais, museus, aeroportos, empregos são muito importantes na vida de todos. O que se deve observar é se estão sendo usados como promessas e, pior, como preço da destruição do meio físico natural, favorecendo a subestimação da dignidade humana.

Esse tipo de desenvolvimento, atrelado ao sentido de crescimento econômico começou a ser posto em questionamento a partir dos anos de 1960, quando se percebeu que

[...] o intenso crescimento econômico ocorrido durante a década de 1950 em diversos países semi-industrializados (entre os quais o Brasil) não se traduziu necessariamente em acesso de populações pobres a bens materiais e culturais, como ocorrera nos países desenvolvidos. (VEIGA, 2005, p. 19).

O programa Índice de Desenvolvimento Humano (IDH), criado por Amartya Sen, no início dos anos de 1990 e lançado pelo Programa das Nações Unidas para o Desenvolvimento (PNUD), tem o propósito de mostrar que é necessário separar esses dois termos, crescer economicamente nem sempre é desenvolver.

[...] ninguém duvida de que o crescimento é um fator muito importante para o desenvolvimento. Mas não se deve esquecer que no crescimento a mudança é quantitativa, enquanto no desenvolvimento ela é qualitativa. (VEIGA, 2005, p. 56).

Em Paracatu, o retorno à exploração aurífera por uma grande empresa criou a expectativa de desenvolvimento econômico que seria expandido ao desenvolvimento social. Enríquez (2011), mostra que

[...] a atividade mineral gera oportunidades (dádiva), porém o aproveitamento delas não ocorre de forma automática, ela é mediada pela ação pública, por intermédio da regulação da atividade e do uso sustentado das rendas minerais [...]. (ENRÍQUEZ, 2011, p. 379).

Há, por parte da empresa, projetos sociais, além da destinação de verbas a ações de cunho sociocultural. Mesmo assim, diante das reais 
necessidades sociais locais e das várias denúncias, por parte de grupos ambientalistas, quanto ao desrespeito da empresa a leis ambientais com práticas de exploração abusiva e perigosa, somada à forma agressiva ${ }^{5}$ como tem avançado sobre as terras das comunidades quilombolas com seu projeto de exploração, deixa a sensação de que tais ações são frágeis e pouco válidas.

Deacordo com Nunes (2010), "a mineração pode ser considerada, genericamente, a atividade de extração que possui valor econômico" (NUNES, 2010, p. 69). Foi e continua sendo de muita importância para o desenvolvimento da humanidade. Pode-se confirmar isso quando se lembra que, através dessa atividade, o homem extraiu da natureza a matéria-prima para a fabricação de utensílios, armas e muito mais, o que serviu de base para seu desenvolvimento técnico-científico. Foi pela exploração mineral que monarquias europeias desbravaram mares nunca antes navegados, dominaram povos e, com a riqueza dessa atividade, atingiram o que ficou conhecido como Revolução Industrial, gerando, a partir daí, boa parte do modo como vivemos hoje.

Outro argumento apresentado pelas próprias empresas em favor da mineração é o de que geram empregos nas regiões onde atuam e, assim, fazem com que a economia circule, proporcionando melhores oportunidades às pessoas. Quanto a isso não há dúvidas, o impasse está no fato de que o número de empregos nem sempre é tão grande quanto alardeiam, em face do grande uso de equipamentos de tecnologia avançada. Para completar esse quadro, a maior parte dos recursos extraídos por essa atividade tem como destino a exportação. Ficando na região apenas o saldo dos impostos previstos pela legislação, quando não deixam, lembrando Prado Junior (1996), "a prodigiosa destruição dos recursos naturais". Para Enríquez (2011, p. 245),

[...] nenhuma sociedade moderna pode prescindir dos bens minerais. Os minerais são necessários a uma vasta gama de atividades humanas, que abrange desde insumos para a agricultura até componentes de computadores.

Não faz parte deste trabalho criticar negativamente a atividade mineradora. Mas preocupa-nos como esta tem sido desenvolvida em Paracatu, principalmente quando seu direcionamento provoca a dizimação das comunidades quilombolas que ali residem há mais de cem anos.

\section{A questão quilombola}

A Constituição de 1988, com seu cunho social, busca reparar os erros cometidos ao longo da história contra as comunidades negras rurais e urbanas. Julgando ainda existir uma dívida deixada pela escravidão, por meio de seu Art. 68 dos Atos das Disposições Constitucionais Transitórias, passa a garantir-lhes o direito a um espaço físico e os institui como novos sujeitos políticos e sociais. Uma inegável oportunidade para que tais grupos pudessem solucionar velhos problemas em relação ao direito a terra, à falta de reconhecimento e da garantia e à ampliação de participação nas políticas públicas desenvolvidas em prol dos mais carentes. Leite (1999) acredita que o ato de inserção do Artigo supramencionado

[...] não foi naquele momento sequer suficientemente percebido nem avaliado pelos setores conservadores que nele votaram. Acreditavam tratar-se de alguns pequenos casos isolados, bons para produzir

5. Essas são denúncias partem de organizações não governamentais locais. Há, atualmente, por parte do Ministério Público e da Advocacia Geral da União um esforço de conciliação entre a empresa e as comunidades quilombolas. Porém, existem várias denúncias no Ministério Público, dos próprios quilombolas, sobre o desrespeito da mineradora para com seus territórios. 
a visibilidade aos atos do governo e para colocar uma pedra definitiva sobre o assunto. (LEITE, 1999, p. 134).

Em conformidade com essa ideia, Arruti (2003, p. 66), diz que "os formuladores da lei não dispunham de elementos suficientes para prever seus efeitos criadores." Situação comprovada quando se observa que, apesar das dificuldades e da falta de clareza que o texto inicialmente apresentou, não tardou para que esses sujeitos se mobilizassem em defesa de seus direitos.

Como resultado dessa mobilização, Estado e governos, embora não imediatamente, tiveram que dar ênfase ao Artigo através da elaboração, primeiramente, do Parecer SAJ 1.490/01, logo em seguida, do Decreto no 3.912, de 10 de setembro de 2001, e, por último, o Decreto no 4.887, de 20 de novembro de 2003, todos com o propósito de regulamentar o procedimento para identificação, reconhecimento, delimitação, demarcação e titulação das terras ocupadas por remanescentes das comunidades dos quilombos. Por último, o Decreto no 6.040, de 2007, que Institui a Política Nacional de Desenvolvimento Sustentável dos Povos e Comunidades Tradicionais.

O esquecimento, isolamento ou até mesmo o descaso - fortemente favorecidos pela ideologia da soberania nacional, que praticamente anulou a diversidade sociocultural e fundiária do país foram, após a Constituição de 1988, dando lugar à visibilidade e reconhecimento da existência não só dos grupos quilombolas, como também dos vários grupos que situam na denominação de comunidades tradicionais. Embora estejamos associando a não visibilidade desses grupos à promulgação de uma nova constituição no Brasil, tais mudanças não foram prerrogativas somente aqui. É notório que, nas três últimas décadas do século $X X$, uma tendência de se repensar a relação dos Estados-nações e suas diversidades identitárias vinha ativando a mobilização de diferentes grupos, em razão de seus reconhecimentos e garantia de direitos.

Reconhecimento e garantias de direitos, dentre eles a posse da terra, tornaramse prioridade para as comunidades de remanescentes quilombolas. Em Paracatu, a Fundação Cultural Palmares já identificou e reconheceu três comunidades de remanescentes quilombolas: Família dos Amaros, Machadinho, São Domingos ${ }^{6}$, com seus territórios aguardando o Relatório Técnico de Identificação e Demarcação (RTDID) pelo Instituto Nacional de Colonização e Reforma Agrária (INCRA) para, definitivamente, tomarem posse da terra. A morosidade do processo tem favorecido geração de problemas entre os quilombolas e a mineradora, que tem avançado sobre o território quilombola, desrespeitando o direito daqueles que querem permanecer na terra. Além disso, no intuito de agilizar a liberação do território para desenvolver livremente suas atividades, a mineradora tem entrado em negociações isoladas de compra e venda com famílias dessas comunidades que, desacreditando na concretização do reconhecimento de seus direitos, preferem ceder aos interesses da mineradora, abandonado a luta pelo direito a terra, uma vez que é mais fácil receber uma boa quantia em dinheiro ${ }^{7}$ pelo pedaço de terra que ocupa. Diante desse fato, órgão e autarquias estataistentam encontrarumasoluçãoqueatenda tanto aos quilombolas quanto à mineradora.

O Decreto no 6.040/2007, que institui a PolíticaNacionaldeDesenvolvimentoSustentável dos Povos e Comunidades Tradicionais, em seu Art. 3o, define Desenvolvimento Sustentável como

[...] o uso equilibrado dos recursos naturais,

6. Há rumores da existência de outras três comunidades, também reconhecidas. Porém, durante a elaboração deste texto, não foi possível confirmar tal informação.

7. Os valores de compra e venda de terras próximas à mineradora aumentaram consideravelmente em Paracatu, diante do fato de a mesma cobrir todas as propostas dos interessados. 
voltado para a melhoria da qualidade de vida da presente geração, garantindo às mesmas possibilidades para as gerações futuras. (BRASIL, 2007).

Várias podem ser as formas dessa melhoria da qualidade de vida, mas para as comunidades em questão, tanto essa melhoria quanto a garantia das mesmas condições para as gerações futuras só poderão ocorrer se essas comunidades estiverem estabelecidas em sua terra. É nesse aspecto que se pode observar o impasse de Paracatu. As terras que são garantias de sobrevivência aos quilombolas, assim como suas tradições e modo diferenciado de viver, também são alvo do interesse de desenvolvimento da mineradora.

Essa situação remete diretamente ao conceito de territorialidade que, de acordo com Albalhi (2004, p. 28),

[...] indica relações entre um indivíduo ou grupo social e seu meio de referência, manifestandose nas mais variadas escalas geográficas - uma localidade ou um país - e expressando um sentimento de pertencimento e um modo de agir no âmbito de um espaço geográfico. [...] Em nível coletivo, a territorialidade tornase também um meio de regular as interações sociais e reforçar a identidade do grupo ou comunidade.

Segundo Sarmento (2008, p. 35),

Para os quilombolas, a terra habitada, muito mais que um bem patrimonial, constitui elemento integrante de sua própria identidade coletiva, pois ela é vital para manter os membros do grupo unidos, vivendo de acordo com seus costumes e tradições.

Contra os interesses da mineradora há, por parte dos próprios quilombolas, denúncias sobre terem recebido ofertas da empresa para que vendam seu imóvel. Os mesmos refutam tais propostas argumentando: "Não queremos sair daqui onde eu e minha família toda nascemos"
(BRASIL, 2011).

Vê-se que a autoidentificação como quilombola passa pela certeza de vínculos entre os elementos do grupo e destes com a terra. Vínculos não se constituem de um dia para o outro; é necessário tempo. A territorialidade pode ser definida "como um conjunto de relações que se originam num sistema tridimensional sociedade-espaço-tempo" (RAFFESTIN apud ALBAGLI, 2004, p. 30).

No mundo da globalização com a imposição de sua racionalidade hegemônica, há a exigência de se abrir espaço para a exploração de cunho econômico e comercial. Movimento dialético necessário para o ordenamento socioeconômico vigente.

Felizmente, a nova política ambiental, somada a uma preocupação social cada vez mais presente nas decisões governamentais, aos poucos tem mostrado a necessidade de se repensar essa hegemonia. Mesmo que para alguns a presença das comunidades quilombolas represente atraso, para outros é necessário protegê-las e lutar por políticas que as beneficiem. No caso de Paracatu, o Ministério Público Federal tem buscado, por meio de audiências de conciliação, aplacar os problemas entre mineradora e quilombolas.

Durante as audiências de conciliação, denúncias mais relevantes por parte das comunidades são referentes à compra de terras nas comunidades pela mineradora. De acordo com fala do procurador da república que acompanha o caso, em audiência, a empresa realizavisitasconstantese pressãoàscomunidades para efetuar as transações (BRASIL, 2011). Para Albagli (2004, p. 37), as práticas de transformações dos elementos naturais por um dado grupo social

[...] podem ser predatórias desses recursos e degradantes da qualidade ambiental; ou sustentáveis do ponto de vista da conservação e do equilíbrio do ambiente local. 
A relação das comunidades quilombolas com seus territórios sempre foram voltadas para essa segunda prática, conforme a ex-ministra Marina Silva:

A existência dessas comunidades, baseadas em sistemas sustentáveis de exploração dos recursos naturais, desenvolvidos ao longo das gerações e adaptados às condições ecológicas locais, desempenha papel fundamental na proteção da natureza e na manutenção da biodiversidade biológica. (SILVA, 2007, p. 7).

$\mathrm{Na}$ contrapartida da certeza de preservação ambiental por parte das comunidades quilombolas, existem as dúvidas em relação à mineração. $O$ impasse gerado na cidade de Paracatu talvez esteja perto de solução, como se observa na fala de um vereador que apresentou proposta de lei complementar limitando a expansão da mineradora, indicando não ser contra a mineradora, apenas esperando que ela não prejudique a cidade e a qualidade de vida dos moradores.

Até o presente momento, a realização das audiências tem servido para elaborar propostas de reordenação ambiental por parte da mineradora, considerando a presença dos quilombolas em sua vizinhança. Porém, a morosidade na solução dos outros problemas como a posse e a garantia das terras por parte de outras autarquias como o INCRA tem criado dúvidas entre aos membros das comunidades, fato possível de se notar no depoimento de Maria Abadia, líder do grupo Família dos Amaros:

De nada valerá todas essa discussão se não chegarmos a um denominador comum, nossa situação é gritante, estamos à margem da mineração bebendo veneno. Quando cansarmos teremos que tomar nossas próprias atitudes $^{8}$.

\section{O caminho para a proposta de sustentabilidade}

É quase impossível encontrar, nos dias de hoje, algum Estado-nação que não demonstre, em seus programas de governo, preocupação com seu espaço ambiental, principalmente no que tange ao desgaste desse espaço e o que será deixado às gerações futuras; situação confirmada não só pela criação de leis, projetos e ações, mas também por um discurso que acabou se convergindo na criação de uma teoria de desenvolvimento sustentável. Tal preocupação não é somente de governos e Estados. A questão ambiental e sua relação com o desenvolvimento, primeiramente econômico e também humano, já vem figurando na pauta dos estudos científicos desde as últimas décadas do século XX. E como se refere Nunes (2010, p. 15), "um lugar comum no qual várias ciências se encontram em função de um mesmo objeto: as "ciências ambientais'". Essa preocupação científica, política e social tem sua razão de ser. $\mathrm{O}$ meio ambiente de que tanto se fala é o meio ambiente ocupado pelos humanos. Uma pergunta metodologicamente simplista que a nosso ver exige uma resposta complexa: por que tanta preocupação? Para Sachs (2000, p. 170), tal preocupação faz parte de

[...] uma nova era do desenvolvimento, depois da "ignorância" e "pobreza" em décadas anteriores, a "sobrevivência do planeta" tende a tornar-se aquela tão divulgada (decantada) emergência dos anos 90 em nome da qual se desencadeou um novo frenesi de desenvolvimento.

Ainda, para o autor, essa nova fase também está ligada "às razões políticas dos países do Hemisfério Norte". A preocupação com a questão ambiental "depende de como as

8. Depoimento proferido em audiência de conciliação realizada em 13 de maio de 2011. 
nações ricas se sentem" (SACHS, 2000, p. 118). É correto o que ele afirma, mas esse novo frenesi tem uma longa caminhada com a participação de países do Hemisfério Sul também. Em 1972 foi realizada em Estocolmo, na Suécia, uma conferência das Nações Unidas sobre Meio Ambiente. A precedência dessa conferência de acordo com Nunes (2010) foi marcada por controvérsias entre países industrializados e países em desenvolvimento - de caráter geopolítico e econômico em que países desenvolvidos tentavam frear $\mathrm{o}$ desenvolvimento industrial dos países em desenvolvimento. O tema central desse debate era quem prejudicava mais o meio ambiente.

Sachs (2000) atribui essa tomada de consciência dos países ricos à onda de denúncias de ambientalistas americanos no New York Times, por meio de artigos que citavam os problemas com a poluição e os desastres provocados pelo homem. Paralelamente a esse fato, uma associação informal, constituída por pesquisadores de diversos países e diversas áreas do conhecimento, reuniu-se em abril de 1968, em Roma, produzindo um relatório intitulado Limites do Desenvolvimento, que tinha como foco central o acelerado ritmo da industrialização mundial, o crescimento demográfico, a destruição generalizada, esgotamento dos recursos naturais não renováveis e deterioração ambiental. Dentre as conclusões a que chegaram, chama a atenção o fato de se preocuparem com uma retomada de um estado de equilíbrio global e por sugerirem que o mundo todo devia se mobilizar em razão de um equilíbrio entre economia e ecologia. $\mathrm{O}$ que foi decidido nesse encontro serviu de base para a Conferência de Estocolmo em 1972. Posteriormente, outra reunião ocorreu em Salzbourg em 1974, na qual se preocuparam, prioritariamente, com a nova ordem mundial.

Vinte anos após a Conferência de Estocolmo, aconteceu a Conferência do Rio de Janeiro, antecedida também por debates entre países desenvolvidos e em desenvolvimento. Desse debate nasceu a Declaração Sobre o Direito ao Desenvolvimento, condição considerada inalienável e indisponível como direito humano e ainda estabeleceu a ligação entre este e o direito ao meio ambiente. Vale a pena ressaltar que tal declaração foi

[...] adotada pela resolução 41/128, de 14.12.1986, com cento e quarenta e seis votos a favor, um único contra (Estados Unidos) e oito abstenções. (Dinamarca, Finlândia, República Federal da Alemanha, Islândia, Israel, Japão, Suécia e reino Unido). (ALVES, 1997 apud NUNES, 2010, p. 47).

A Conferência das Nações Unidas sobre Meio Ambiente e Desenvolvimento (CNUMAD), também chamada de ECO/92 e Rio 92 - uma tentativa de rever o fracasso da aplicação das medidas adotadas na Conferência de Estocolmo - exigiu, antes, das ONU uma preparação que envolveu a criação de um Comitê Preparatório e uma Comissão Mundial sobre Meio Ambiente e Desenvolvimento, composta por 21 membros. Não se pode dizer que a antecedência dessa conferência foi marcada somente pelo insucesso da Conferência de Estocolmo. O progresso da Conferência Sobre o Direito ao Desenvolvimento e do Relatório de Brundtland (Gro Harlem Brundtland, que presidiu juntamente com Manson Khalid a Comissão Mundial Sobre Meio Ambiente e Desenvolvimento) favoreceu a incorporação do tema Desenvolvimento Sustentável entre os objetivos da Conferência Rio 92. Não cabem aqui, mais aprofundamentos sobre a referida conferência. Apenas o destaque de que foi a que comportou, até o momento, o maior número de Chefes de Estado, cerca de 100, com participação efetiva de 178 governos. Diferenciou-se da Conferência de Estocolmo também no tema central, pois, enquanto naquela destacouse o problema ambiental, nesta, destacou-se o problema ambiental e o desenvolvimento. 
Chega-se ao século XXI, e a Conferência Mundial Sobre Desenvolvimento Sustentável, ocorrida em 2002, em Johanesburgo, na África do Sul, buscou reafirmar os princípios adotados em 1992 no Rio de Janeiro, além dos contidos na Declaração do Milênio (2000, p. 52-53) no que se refere

[...] às relações internacionais do século XXI: liberdade; igualdade; solidariedade; tolerância; respeito à natureza [...] em uma perspectiva sustentável; divisão de responsabilidades econômicas e sociais entre os Estados.

Também foram produzidos documentos que destacavam questões importantes como:

[...] erradicação da pobreza; mudança dos padrões insustentáveis de consumo e produção; proteção e conservação dos recursos naturais como base do desenvolvimento econômico e social; inseparabilidade da paz e do desenvolvimento sustentável; combate à fome crônica, às ocupações estrangeiras, aos conflitos armados, ao tráfico ilícito de entorpecentes, ao crime organizado, ao terrorismo, às doenças crônicas e contagiosas - especialmente AIDS, malária e tuberculose; ênfase ao princípio da responsabilidade comum, mas diferenciada [...]. (NUNES, 2010, p. 53).

Essa conferência não atingiu o esperado no sentido de ter o apoio dos EUA na adoção do Plano de Implementação, já que o país manteve sua posição de não aceitação de que todos os Estados têm responsabilidades comuns na redução da degradação ambiental, mas diferenciadas, exigindo que países subdesenvolvidos tenham as mesmas responsabilidades que os desenvolvidos. Nesse sentido, a realidade dos fatos aponta que a Teoria de Desenvolvimento Sustentável é um tanto quanto frágil e já nasceu pobre e sem o devido apoio para se firmar imediatamente. Veiga (2005) acredita que os teóricos do desenvolvimento sustentável ainda não conseguiram desvendar o enigma do novo mundo que se avizinha. Parece que agem como os utópicos do século XIX, que tentavam "antecipar os inúmeros aspectos da modernidade". (VEIGA, 2005, p. 208).

A Conferência de Joanesburgo mostra que, à medida que os debates sobre meio ambiente, recursos naturais, desenvolvimento econômico e desenvolvimento humano foram acontecendo, foi-se ampliando a visão de quão complexa é a relação humana com os recursos oferecidos pelo planeta e com seus próprios pares. Também não se discutirá aqui que o que pauta essas duas relações é a exploração. Na esteira desse longo discurso, chegou-se a essa nova teoria: a Teoria do Desenvolvimento Sustentável, síntese de tudo o que vem sendo debatido sobre as referidas relações.

[...] um imperativo global que chegou para ficar, em virtude da percepção de que a biosfera, em nível global, regional e local, está sendo submetida a pressões insuportáveis e prejudiciais para o próprio desenvolvimento e as condições de vida. (VEIGA, 2005, p. 187).

Vários são os conceitos cunhados para o termo "desenvolvimento sustentável", mas, tão importante quanto os conceitos são os elementos que os compõem, por isso destacamos o que Nunes (2010, p. 39) apresenta como elementos mais relevantes das várias acepções sobre o termo:

[...] a) crescimento econômico, ou expansão econômica; b) satisfação de necessidades do presente; c) preservação dos recursos naturais no presente e para as gerações futuras (exploração equilibrada).

Objetivar um desenvolvimento sustentável exige repensar o modelo econômico hegemônico ocidental. O que ocorre em Paracatu reflete bem os motivos dessa necessidade. A mineradora aí sediada prevê em seu site que a exaustão da mina, que seria para 2016, tem projeção para 
continuar até 2040, sendo que o minério que hoje é explorado, em torno de 17,2 milhões de toneladas por ano, passará para uma capacidade de 61 milhões.

Questiona-se: como desenvolver com sustentabilidade, se a previsão é de aumento de produção, e, consequentemente, aumento da exploração? Para a ampliação da produção, comunidades vinculadas a terra terão de ser sacrificadas? Os limites da natureza expressam os limites da humanidade e

[...] os limites do crescimento econômico mais do que materiais - são sociais. Sem a adoção de políticas de caráter distributivo, equânime e que almejem uma justiça ambiental, não há sustentabilidade. (NUNES, 2010, p. 56).

Essa realidade sugere dúvidas quanto à proposta de sustentabilidade. E, mais ainda, quanto ao desenvolvimento sustentável proposto para as comunidades quilombolas. Dúvida mantida mesmo diante do expresso por Veiga (2010, p. 192), que considera que a projeção do termo

[...] constitui sinal bastante auspicioso. Indica, entre outras coisas, a extensão da tomada de consciência de boa parte das elites sobre a problemática dos limites da natureza.

Preocupar-se com o meio ambiente é também preocupar-se com a falta dos recursos que o meio pode oferecer para a sobrevivência humana.

\section{Considerações Finais}

A titulação de uma terra como pertencente a um grupo quilombola é um processo moroso e burocrático. E exige desses grupos submissão a determinações legais, que em muitos casos, são de difícil compreensão até para especialistas que dirá para pessoas iletradas como são, na maioria dos casos, os quilombolas. Em contrapartida, há uma diversidade de formas no viver, ser e saber quilombola.

A grande maioria dessas comunidades vive, no cotidiano, alguma forma de opressão por exigirem ou necessitarem de direitos específicos. Apesar da existência de legislação estabelecida pela própria Constituição em seu Art. 68 dos ADCT, do Decreto 4.887, de 2003, que regulamenta tal artigo, casos que vão da violência física à exclusão e humilhação social ainda ocorrem com essas comunidades. Os quilombolas de Paracatu não estão livres de pressões, mas já contam com fortes aliados, e conjuntamente têm buscado o caminho da conciliação. Embora ainda tenham pela frente o processo de titulação e garantia para retornarem ao seu território de origem ${ }^{9}$. A mineração, mesmo sendo predatória, ainda é uma boa alternativa para o desenvolvimento econômico e, consequentemente, desenvolvimento social das comunidades, desde que repensada sua forma de extração e mais bem planejada a distribuição dos lucros advindos dessa atividade.

Em Paracatu, a população já começa a se mobilizar no sentido de exigir procedimentos menos agressivos por parte da mineradora. Reuniões na Câmara Municipal para debater esse problema e maior transparência em relação às audiências de conciliação entre a mineradora e as comunidades quilombolas locais já demonstra um significante nível de reconhecimento da necessidade da participação na defesa do ambiente em que vivem. Quanto à sustentabilidade ambiental local, frente aos projetos da mineradora, muitas são as dúvidas, pois, mesmo com os acordos firmados nas já citadas audiências,

9. Em Paracatu, apenas a comunidade quilombola São Domingos permanece em seu território de origem. As comunidades Machadinho e Família dos Amaros esperam pela titulação de seu território para que possam retornar à terra. 
ela continua suas atividades sem a menor das alterações. Repetindo o que ocorre nas grandes conferências internacionais em que os países mais ricos participam, ouvem, dizem entender, mas não assumem compromissos em conjunto com os demais.

A despeito dessas atitudes e mesmo da fragilidade do projeto de desenvolvimento sustentável, é inegável o quanto o mundo todo tem se preocupado com a criação de políticas de proteção ambiental. Da mesma forma, cada vez mais grupos sociais têm se unido para enfrentar os que não aceitam essa nova proposta. Ainda não foi possível visualizar os resultados do embate que ocorre em Paracatu. Da mesma forma que os quilombolas têm a seu lado instituições oficiais do Estado, o mesmo se dá com a mineradora que, oficialmente, cumpre com todas as exigências para sua prática. A única conclusão que se pode obter até o momento é que, mesmo com as mobilizações e açõesdopoderpúblico, a mineradorajáconseguiu deslocar duas das comunidades quilombolas do local e avançar sobre um bairro inteiro da cidade.

\section{Referências}

ALBAGLI, S. Território e territorialidade. In: LAGES, V.; BRAGA, C.; MORELLI, G. (Org.). Território em movimento: cultura e identidade como estratégia de inserção competitiva. Rio de Janeiro: SEBRAE, 2004.

ARRUTI, J. M. Relatório técnico-científico sobre os remanescentes da comunidade de Quilombo de Cangume, município de Itaóca-SP. 2003. Disponível em: < http://www.itesp.sp.gov.br/br/info/ acoes/rtc/RTC_Cangume.pdf>. Acesso em: 20 mar. 2012.

BRASIL. Advocacia Geral da União. Relato de Luiza Ferreira Gomes, quilombola que mora na comunidade. Disponível em: <www.agu.gov.br >. Acesso em: 23 de março de 2011.

BRASIL. Decreto no 6.040, de 7 de fevereiro de 2007. Institui a Política Nacional de Desenvolvimento Sustentável dos Povos e Comunidades Tradicionais. Disponível em: < <http://www.planalto.gov.br/ ccivil_03/_ato2007-2010/2007/decreto/d6040.htm>. Acesso em: 20 mar. 2012.

DECLARAÇÃO do milénio. 2000. Disponível em: < http://www.unric.org/html/portuguese/uninfo/ DecdoMil.pdf>. Acesso em: 23 mar. 2012.

ENRÍQUEZ, M. A. R. da S. Maldição ou dádiva: os dilemas do desenvolvimento sustentável a partir de uma base mineira. São Paulo: Signus, 2011.

ENRÍQUEZ, M. A. R. da S. Mineração e desenvolvimento sustentável: é possível conciliar? Revista Iberoamericana de Economía Ecológica, México, v. 12, p. 51-66, 2009.

ENRÌQUEZ, M.A.R. da S.; DRUMOND, J. A. Mineração e desenvolvimento sustentável: dimensões, critérios e propostas de instrumentos. In: LUZ, A. B. da (Org.). Tendências tecnológicas: Brasil 2015. Geociências e Tecnologia Mineral. Rio de Janeiro: CETEM, 2007.

FURTADO, C. O mito do desenvolvimento econômico. São Paulo: Paz e Terra, 1981.

ILLICH, I. Necessidades. In: SACHS, W (Org.). Dicionário do desenvolvimento: guia para o 
conhecimento como poder. Petrópolis: Vozes, 2000.

LEITE, I. B. In: FONSECA, C. (Org.). Horizontes antropológicos: diversidade cultural e cidadania. Porto Alegre: Editora da UFRGS, 1999.

NUNES, P. H. F. Meio ambiente \& mineração: desenvolvimento sustentável. Curitiba: Juruá, 2010. PRADO JÚNIOR, C. Formação do Brasil contemporâneo. São Paulo: Brasiliense, 1996.

RAHNEMA, M. Pobreza. In: SACHS, W (Org.). Dicionário do desenvolvimento: guia para o conhecimento como poder. Petrópolis: Vozes, 2000.

SACHS, W. Meio Ambiente. In: SACHS,W. (Org.). Dicionário do desenvolvimento: guia para o conhecimento como poder. Petrópolis: Vozes, 2000.

SARMENTO, D. Territórios quilombolas e constituição: a ADI 3.239 e a constitucionalidade do Decreto 4.887/2003. 2008. Disponível em: <http://6ccr.pgr.mpf.mp.br/documentos-e-publicacoes/ docs_artigos/Territorios_Quilombolas_e_Constituicao_Dr._Daniel_Sarmento.pdf > . Acesso em: 20 mar. 2012.

SEN, A. K. Desenvolvimento como liberdade. São Paulo: Cia. das Letras, 2008.

SILVA, M. Saindo da invisibilidade: a política nacional dos povos e comunidades tradicionais. Inclusão Social, Brasília, v. 2, n. 2, p. 7-9, abr./set. 2007.

VEIGA, J. E. Desenvolvimento sustentável: o desafio do século XXI. Rio de Janeiro: Garamond, 2005.

Submetido em 27 de março de 2013.

Aprovado em 28 de maio de 2013. 